\title{
Significance and Usefulness of Guidelines
}

\author{
Hans-Jörg Senn \\ Tumor Center ZeTuP (Tumordetection, Treatment and Prevention), St. Gallen, Switzerland
}

Well into the second half of the 20th century, physicians - and especially surgeons - were used to treat their patients 'optimally' on the basis of their own accumulated professional experience, and as they got older and even more experienced, with an ever increasing conviction that what they decided for their patients was 'the right way' to proceed. And patients in general were happy with this paternalistic decision-making model, as it left them with confidence that their favourite doctor was fully aware of what was best for them. Today, many of us - especially in oncology - see themselves confronted with newly diagnosed or just operated cancer patients and their suspicious relatives, eagerly questioning whether the treatment proposed to them would really fulfil internationally recognised standards and guidelines, which they would have searched themselves in the internet! What has happened to medicine and society in between?

During the last 3-4 decades, this nearly idyllic decision-making platform of yesterday has greatly changed, professionally and politically. No other field in medicine has experienced - and even actively promoted - this change in decision-making as extensively as clinical oncology, especially in the domain of breast cancer treatment [1]. Starting during the seventies and eighties of the 20th century, a huge wave of prospective randomized clinical trials has swept over the oncology treatment scene, sometimes leaving physicians and cancer patients confronted with more questions than answers about the optimal diagnostic work-up and especially about the best treatment pathway. The procedure of random allocation of different treatment options for the same disease stage, promoted with enthusiasm to terminate the frequently biased decision-making 'by conviction' was creating in itself a new area of uncertainty - but admittedly on a higher level! For even randomised trials about the same problem may lead to divergent and even contradictory results. In addition, randomised trials - although clearly indispensable for medical progress - are not completely free of biased design and execution, regardless of whether they are initiated and/or financed by neutral academic sources, by industry or by both. Even the (very variable) definition and application of 'levels of evidence' could not completely solve this problem, although the evolution of evidence-based medicine in general and the formulation of 'minimal clinical standards' by oncology societies was a step in the right direction [2].

It is on this background of increasing 'confusion' about the interpretation and implementation of trial outcome and problems of translation into clinical medicine, that the institution of meta-analysis and so-called overviews, for example EBCTCG/Oxford [3] as well international consensus panels such as St. Gallen [4] for the treatment of breast cancer have developed during the last 20 years. While meta-analyses of trials in a given disease state are able to provide a useful database for treatment recommendations, guidelines for specific treatments that are useful and generally acceptable for the optimal treatment of major neoplastic conditions, have to be developed by other than just purely statistical procedures, usually national or international expert consensus panels. Besides the trial application problem mentioned above, other - legal, social and economic - pressures in modern medicine have also contributed to increasing standardisation of diagnostic and especially therapeutic procedures in modern medicine, and especially oncology.

Using the term 'guidelines', confusion starts again to mount, as this term has different meanings in different countries and professional settings. To some, they are just a 'range of opinions' helpful in decision-making [5], to others they represent nearly legal authority and tend to be the base for financial reimbursement of medical procedures [6]. But according to most, guidelines today are necessary and useful cornerstones to delineate meaningful directions on how to proceed surgically and/or medically in a given disease state, defined by presently known major risk factors. Guidelines define a some-

\begin{tabular}{ll}
\hline KARGER & @ 2006 S. Karger GmbH, Freiburg \\
Fax +49 76145207 14 & Accessible online at: \\
$\begin{array}{l}\text { E-mail Information@Karger.de } \\
\text { www.karger.com }\end{array}$ & www.karger.com/brc
\end{tabular}

Prof. Dr. med. Hans-Jörg Senn

Zentrum für Tumordiagnostik + Prävention (ZeTuP)

Rorschacherstrasse 150, 9006 St. Gallen, Switzerland

Tel. +41 71 243-0043, Fax -0044

E-Mail hjsenn@sg.zetup.ch 
how safe range of scientifically possible and legally acceptable treatment options for patients and doctors. They should enable physicians to integrate the (confirmed) progress of clinical research into daily practise [1]. To be generally helpful and as unbiased as possible, such guidelines can hardly be extrapolated by authors of single (even large, so-called pivotal) trials. They need to be developed and confirmed by hopefully 'neutral' (non-restricted) and geographically as well as scientifically well chosen panels of experts in the field. Their task and interest should not be the 'defence' of their own trial achievements and findings, but rather the critical positioning of all relevant data in the field and the estimation of their general relevance for clinical progress.

Nobody today would probably dispute the necessity and value of (especially therapeutic!) guidelines in clinical oncology, where too many questions still are open and where increasing cure and promoting efficient care are badly needed. But the usefulness of guidelines depends greatly on certain basics, which might be summarised as follows:

- Adequate background of evidence-based data (preferably from several randomised trials with conform outcome) in a well defined, extensively studied disease state.

- Adequate number of respective publications (not just early abstracts and/or oral communications, which might be subject to change in further analysis).

- Adequate follow-up intervals of data evaluated (this is ever more important regarding the present strategy of industry to promote premature and potentially clinically irrelevant trial 'significance' in mega-studies).

- Careful and critical interpretation of fully presented data by a scientifically and politically neutral, well selected panel of clinical experts in the field, with the inclusion of related non-clinical professionals (pathologists, epidemiologists, statisticians), possibly also with the inclusion of respective patient advocates (such as 'Europa Donna', or similar).

- Meaningful selection of realistic time-intervals for updating of guideline recommendations by the responsible panel/society, which greatly depends on the pace of scientific progress in the field (example: the intervals for convocation of the international St. Gallen consensus panel for primary treatment of early breast cancer had to be shortened from 4 years (in the 1980s) to 3 years (in the 1990s) to bi-annually since 2001, due to accelerated research progress).

- Efficient publication and promotion of guidelines/recommendations among the envisaged target population (national, international, professional).

Clinically useful and practical guidelines are not 'cutting-edge' research outlines, forced to integrate the very latest news of potentially successful therapeutic developments in the field. On the contrary: generally useful guidelines have to be realistically developed for clinical practise, that is for the treating physicians of the $80-90 \%$ or even more patients, who are treated outside of prospective clinical trials in most countries worldwide. However, the process of developing and updating therapeutic guidelines in consensus or respective expert panel meetings, can greatly facilitate the evolution of clinical research at a national or international level [7]. We are experiencing this 'cross-fertilisation' process extensively and repeatedly in the preparation phase of the bi-annual St. Gallen international breast cancer treatment consensus meetings in close cooperation with major international breast cancer study groups $[7,8]$.

There is no general agreement as to the extent and format of guidelines except for the fact that such guidelines - if not adequately presented and understandable - are simply not integrated or followed by the medical community. Industry, which in my opinion should have no role in setting up commercially neutral guidelines and clinical recommendations, could however greatly influence their implementation and distribution among physicians, surgeons and related healthcare professionals once they are finalised. Many clinicians today, especially in German speaking European countries are still afraid of 'general guidelines' (see above) as they feel constricted in individual decision-making for their patients. However, there is no question that the integration of responsibly developed guidelines into clinical medicine has already greatly influenced the way of medical decision-making in our countries and this diagnostic and especially therapeutic standardisation is increasingly recognised as one of the driving forces of quality progress and control in modern oncology. Unfortunately, guidelines are followed irregularly in various countries and mechanisms of better implementation of respective guidelines will have to be improved by more appropriate education [9-11].

However, guidelines, notwithstanding the need and advantages of improving treatment standardisation and outcome, should always leave the treating physician - and also the involved patient! - with a certain 'choice of acceptable options' in treatment of a given disease state. Guidelines are here to stay and they will most probably become even more important in the future, as professional and financial resources in medicine could get even more restricted than today. Guidelines protect the individual (patient and treating physician) from suboptimal decision-making and treatment outcome, and they protect society and health systems from unnecessary allocation of resources for unqualified treatments - and thus from unjustified losses. 


\section{References}

1 Thürlimann B, Koberle D, Senn HJ: Guidelines for the treatment of postmenopausal women with endocrine-responsive breast cancer: Past, present and future recommendations. Europ J Cancer 2006 (submitted).

2 Pestalozzi BC, Luporsi-Gely E, Jist LM, Bergh J: ESMO guidelines taskforce: ESMO minimum clinical recommendations for diagnosis, adjuvant treatment and follow-up of primary breast cancer. Ann Oncol 2005;16 (Suppl 1):7-9.

3 Early Breast Cancer Trialists' Collaborative Group (EBCTCG): Effects of chemotherapy and hormonal therapy for early breast cancer on recurrence and 15-year survival: An overview of the randomised trials. Lancet 2005;365:1687-1717.
4 Goldhirsch A, Glick JH, Gleber RD, Senn HJ: Meeting highlights: International St. Gallen Consensus Panel on the treatment of primary breast cancer. J Nat Cancer Inst 1998;90:1601-1608.

5 Goldhirsch A, Glick JH, Gelber RD et al.: Meeting highlights: International expert consensus on the primary therapy of early breast cancer 2005. Ann Oncol 2005;16:1569-1583.

6 Anonymous: Deutsches Arzneimittel-Telegramm, März 2006.

7 Senn HJ, Thürlimann B: The international breast cancer treatment consensus St. Gallen 2005: Departure to new risk selection and new treatment options. Breast 2005;14:427-428.
8 Piccart MJ, de Valeriola D, Dal Lago L et al.: Adjuvant chemotherapy in 2005: Standards and beyond. Breast 2005;14:439-445

9 Roila F, Ballatori E, Patoia L et al.: Drug utilization review team in oncology. Adjuvant systemic therapies in women with breast cancer: An audit of clinical practice in Italy. Ann Oncol 2003;14:843-848.

10 Hébert-Croteau N, Brisson J, Latreille $\mathrm{J}$ et al. Compliance with consensus recommendations for systemic therapy is associated with improved sur vival of women with node-negative breast cancer. J Clin Oncol 2004;22:3685-3693.

11 Bloom BS, de Pouvourville N, Chatre S et al. Breast cancer treatment in clinical practise com pared to best evidence and practise guidelines. $\mathrm{Br} \mathrm{J}$ Cancer 2004;90:26-30. 